\title{
STRUCTURAL DEFORMATION OF THE RUSSIAN ECONOMY IN THE CONTEXT OF GLOBAL CHALLENGES
}

\author{
Viktor Barkhatov $^{1}$, Iuner Kapkaev ${ }^{2}$, Daria Benz ${ }^{3}$, Pavel Kadyrov ${ }^{4}$
}

\begin{abstract}
The objective of the study is to determine the nature of heterogeneous structural deformations in the economy of Russia. The structural deformations result from the development strategy formed during the transitional period in the 1990s. Implementation of the strategy caused an increase in investment in the commodity sector along with its shortage in the hightech sector; it resulted in a low knowledge-intensity level of the Russian production which became uncompetitive both on the domestic and global markets. The article covers all the aspects of the structural deformations in the Russian economy including the preconditions for these deformations to arise.
\end{abstract}

JEL Classification Numbers: F02, F62, F63, DOI: 10.12955/cbup.v7.1335

Keywords: The structure of the national economy, structural deformation, structural shift, global challenges.

\section{Introduction}

Today the development of any country is generally determined by economic structure and how well it was formed. The modern world is being constantly challenged by global economic shocks caused by transformational processes in the economies of major countries. The assessment of the current proportions in national economy, determination of general reference points for future transformations, and the results of the transformations are the key factors for a nation's development. Priorities in structural policy formation as well as in interindustry balance modeling are unique for every country and determined by the nation's historical and economic background.

The Russian Federation, in modern conditions, badly needs structural transformations in its economy. Problems that accumulated during the decades of the Soviet Union's existence were immensely aggravated by a sharp transition from the command-administrative system to a market economy. The market mechanism formed in Russia is actually incapable of creating conditions for progressive structural changes, which are necessary for the Russian economy. The current strategy of socioeconomic development is based on an export-driven approach, and as a result, cannot generate innovative ways of development and respond appropriately to global challenges.

Our research is aimed at revealing the current structural disproportions in the Russian economy, to determinate objective perquisites for these disproportions, and to estimate how strongly global economic shocks influence the Russian economy.

\section{Literature review}

The issue was explored by the representatives of different economic schools of thought. The works of F. Quesnay (1960) made significant contributions to research of structural deformations in national and global economies. He structured basic proportions and directions of GDP realization. K. Marx and F. Engels (1964) made an attempt to discover dynamic structural deformations. The new approach differed from their predecessors in that they analyzed structural processes in dynamics, not in statics. J.B. Clark (1886) in his proceedings on economic statics and dynamics analyzed economic development prerequisites. He discovered that structural disbalance is caused by disproportions between different sectors of the economy.

Today, in transforming economies the influence of cyclic dynamics on structural shifts cannot be underestimated. I. Schumpeter (1982) made fundamental contributions to understanding the cyclical regularities in structural development of the socio-economic system. He claimed that the formation and functioning of a market economy in Russia requires the renewal of a theoretical basis for the impact of cyclical dynamics on structural characteristics of economic development.

\footnotetext{
${ }^{1}$ Institute of Economy, Business and Administration, Chelyabinsk State University, Chelyabinsk, Russia, ecoba@csu.ru

${ }^{2}$ Institute of Economy, Business and Administration, Chelyabinsk State University, Chelyabinsk, Russia, zam@csu.ru

${ }^{3}$ Institute of Economy, Business and Administration, Chelyabinsk State University, Chelyabinsk, Russia, benz@csu.ru

${ }^{4}$ Institute of Economy, Business and Administration, Chelyabinsk State University, Chelyabinsk, Russia, pavel@csu.ru
} 
Forecasting structural dynamics in accordance with cyclical regularities of economic development is of great importance. The works of K. Clark, M. Porat, and D. Bell (1999) pay great attention to the models of structural development within constantly progressing and actively reforming economic systems. The provisions of these works served as the starting point for further research of structural shifts; they also contributed a to better understanding of the technological basis deformations and transformations under the influence of changes in an institutional environment.

Since the beginning of economic reforms in Russia, the theory of structural deformations in aspects of reproduction, investment, and commodities was developed by Russian economists (Glazyev, 2008; Yakovets, 2002; Danilov-Danilyan, 2001; Kondratyev, 2002; May, 2006). However, the level of knowledge in structural deformations regularities of the Russian economy in conditions of financial crisis and in post-crisis Russia remains insufficient. Therefore, the necessity of a technological basis reformation, aimed to modernize the material-production sphere, is still an issue of great importance.

The table below provides key figures of economic development in Russia during the period of 19932015. It supports the thesis about the necessity of a technological basis reformation, aimed to modernize the material-production sphere.

Table 1: Key indicators of economic development in dynamics during the period 1993-2015 (percentage of the same indicator in 1990)

\begin{tabular}{|l|l|l|l|l|l|l|l|l|l|l|}
\hline & 1993 & 1995 & 1998 & 2000 & 2005 & 2008 & 2009 & 2010 & 2013 & 2015 \\
\hline Industrial output & 64.9 & 49.7 & 46.2 & 54.2 & 72.7 & 83.0 & 74.1 & 79.5 & 86.7 & 89.0 \\
\hline Agricultural production & 82.7 & 67.0 & 56.0 & 61.9 & 71.2 & 84.1 & 85.3 & 75.7 & 94.1 & 98.4 \\
\hline Fixed investment & 44.9 & 30.7 & 21.0 & 25.9 & 42.5 & 67.9 & 58.7 & 62.4 & 73.7 & 73.6 \\
\hline $\begin{array}{l}\text { Real (disposable) income of } \\
\text { the population }\end{array}$ & 51.1 & 40.0 & 32.8 & 36.7 & 63.5 & 82.7 & 85.3 & 90.3 & 98.0 & 99.8 \\
\hline \multicolumn{7}{|l|}{ Source: Rusian statitics } \\
\hline
\end{tabular}

Source: Russian statistics annual, Russia in numbers

According to Table 1, for the last 25 years the key economic indicators in Russia didn't even reach the level of 1990; at the same time the economy obviously drifts to simplification. Qualitative economic development depends on technological equipment of industrial production which determines the role of the high-tech sector in its hierarchy (aviation industry, radio industry, communications industry, electronic engineering, rocket and space industry, defense industry). All these spheres are based on mechanical engineering which represents $30-50 \%$ of industrial production indicator in developed countries.

Table 2 provides data on the structure of industrial production in Russia during the period 1990-2015

Table 2: Structure of industrial production in Russia. 1990-2015 (\%)
\begin{tabular}{|l|l|l|l|l|l|l|}
\hline Industries & 1990 & 1995 & 2000 & 2005 & 2010 & 2015 \\
\hline Industrial output, total & 100.00 & 100.00 & 100.00 & 100,00 & 100.00 & 100.00 \\
\hline Electricity and fuel industry & 10.4 & 25.6 & 25.4 & 26.8 & 25.0 & 28.7 \\
\hline Ferrous and nonferrous metallurgy & 10.3 & 13.9 & 15.8 & 13.9 & 13.3 & 9.5 \\
\hline Chemical and petrochemical industry & 6.9 & 7.1 & 6.2 & 6.4 & 7.0 & 6.4 \\
\hline Mechanical Engineering and Metalworking & 28.0 & 16.0 & 16.4 & 13.0 & 13.8 & 14.0 \\
\hline Timber industry, pulp and paper industry & 5.2 & 4.6 & 4.0 & 3.4 & 3.3 & 2.6 \\
\hline Building materials industry & 3.4 & 4.3 & 2.4 & 3.1 & 4.1 & 2.9 \\
\hline Light industry & 11.0 & 2.2 & 1.4 & 0.8 & 0.7 & 0.7 \\
\hline Food industry & 12.1 & 10.6 & 11.1 & 10.9 & 10.8 & 10.4 \\
\hline Soury
\end{tabular}

Source: Russian statistics annual, Russia in numbers

Table 2 demonstrates the reorientation of industrial sector in Russia. During the reforms of the 1990s industrial production moved towards the commodity sector. The share of the fuel industry tripled and investment in fixed capital fell by half. Therefore, by 2015 the share of machine building and metal working of the total industrial production was only $14 \%$ which is 3-4 times lower in comparison with most developed countries.

The process of simplification affected not only industrial production, but also foreign trade, and at that mostly exports. While $85 \%$ of country's exports consists of mineral resources, metals, and timber, the share of industrial production indicating scientific and technological progress decreased from $20 \%$ to 
$5 \%$. Significant deterioration of the quality of fixed capital - the basis for economic development - was caused by a $50 \%$ depreciation. During the years of reforms maintaining physical volume of fixed capital was accompanied by unprecedented decrease of investment. In 2015 this indicator amounted to 73.7\% from the same figures in 1990. At the same time moral and physical deterioration affected the working part of production funds. As a result, Russia's production cannot be competitive in technological and high-tech sectors. While the share of the USA and Japan in global science-intensive production market accounts for $36 \%$ and $30 \%$ respectively, Russia's share is lower than $1 \%$.

According to V. Barkhatov and D. Pletnev (2016) one of the key factors determining the content of structural changes on the regional and national level is a set of historical activities, traditional for every economic system. The authors explore the specificity of small and medium-sized businesses in different regions of the world. The research discovers that modernization of the material production sector is initiated basically by small and medium-sized businesses which also promote innovations capable to change industries fundamentally.

In the study performed by D. Benz and E. Silova (2015), small and medium-sized enterprises are considered as the key factor in the process of overcoming negative structural shifts in the national economy. In this research, small and medium entrepreneurships - fundamental for economic development - are considered from the point of view of national food security, which means that the agricultural sector was involved. The authors reveal that agriculture is the main source of welfare, because surpluses are created directly by farmers, providing the whole society with goods and becoming a central part of any economy. As the majority of agricultural enterprises represent small and mediumsized businesses, it can be said that innovative production is majorly provided by small and mediumsized entrepreneurship.

Nevertheless, it should be taken into account that according to its historical background Russia isn't built on small and medium-sized businesses. The national economy of Russia is based on large businesses. Small businesses in Russia are incapable of providing technological breakthrough because of a lack of financial resources, at the same time large businesses cannot be considered as a source of innovations. These two factors represent the main dilemma of the Russian economy.

Barkhatov et al. (2018) provide detailed analysis of Russian large business innovative potential on a regional scale. The authors identify leading enterprises and reveal their competitive advantage. Then the research explores the scientific and technological capacity of Russian large enterprises, and reveals their impact on quantitative and qualitative indicators of the national economy structure. Studying state capitalism, the authors justify its importance for the Russian economy, determining fundamental contradictions and driving forces within the new paradigm.

Let's consider intermediate results. Structural deformation of the Russian economy implies certain disproportions which cause distortion of its structure, changes in the scale of industries, loss of certain elements, transformations of interactions between the elements (objects and subjects), critical disruption of reproduction, and growth of social tensions. Therefore, structural deformations may threaten national security.

\section{Data and methodology}

Analytical articles and Op-Eds devoted to the analysis of structural deformations in a national economy, the determination and classification of contradictions in economic structure, the definition of proportions of structural elements in a national economy, and the influence of innovations on changes in technological paradigm of a national economy, serve as the theoretical and methodological base for this research. The information basis of this research is represented by official statistical information from the Federal State statistics service; training materials provided by the Government of the Russian Federation, Ministry of economic development, Ministry of Industry and Trade, Court of Auditors; publications from scientific conferences and seminars; analytical compilations; audit reports; and accounting records provided by enterprises from different industries. The actual structure of the whole Russian economy and the intra-industry structure are formed on the basis of the All-Russian Classifier of Economic Activities (RCEA). According to the methodology of optimal structure of national economy identification developed by Sukharev (2009) we determine the key points of structural deformation of the Russian economy between 1995 and 2012. 


\section{Results}

Figure 1 shows the results of the statistical data analysis and demonstrates dynamic comparative structural changes in the economy of Russia from 2014-2018.

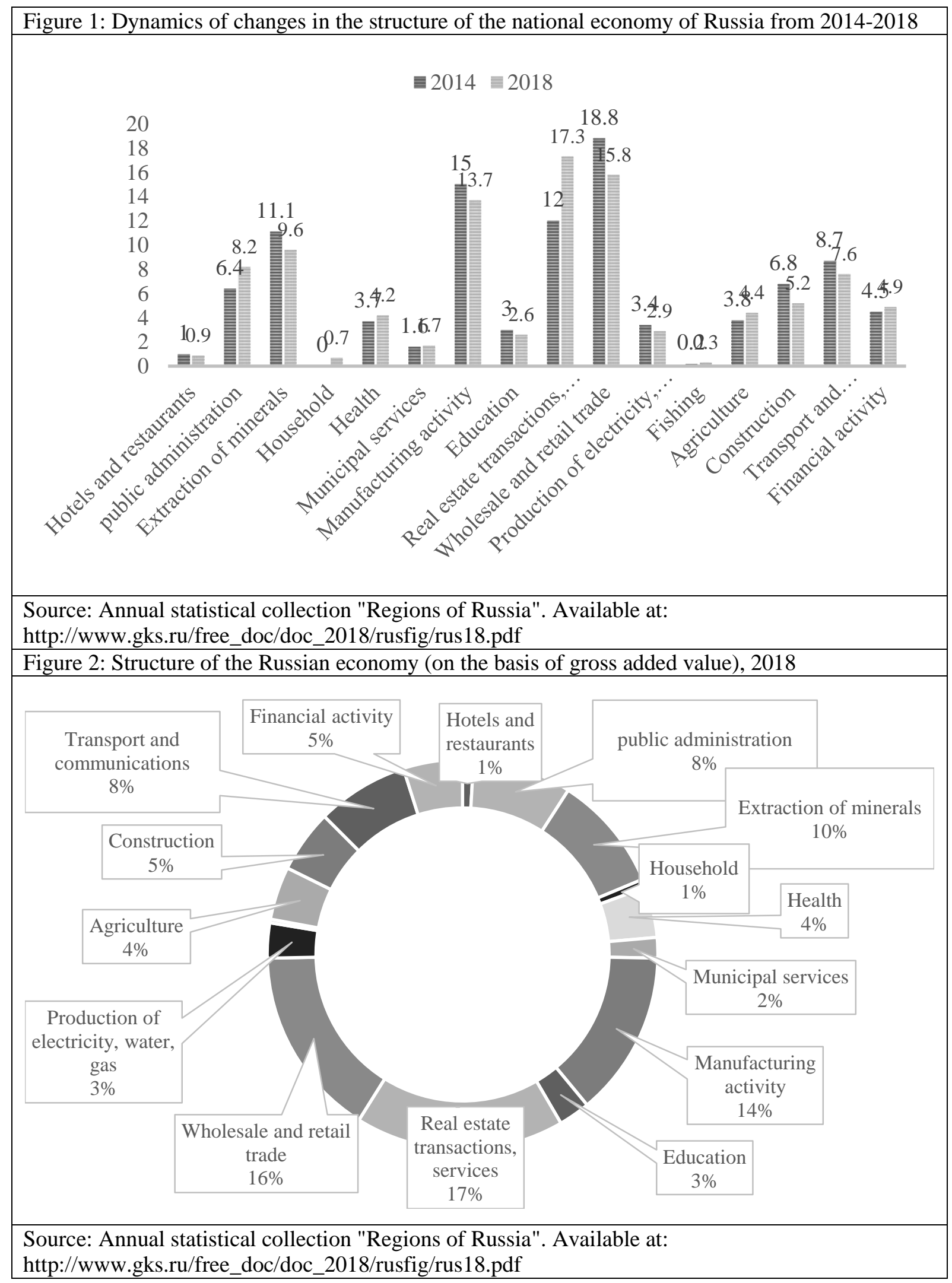


Figure 2 displays the structure of the Russian economy in 2018. We can single out dominating sectors, such as real estate transaction services, wholesale and retail trade, and manufacturing activity. Health care, education, and agriculture are among the least developed sectors.

As mentioned before, the methodology of structural analysis developed by Sukharev (2009) allows us to identify the key points of structural deformation, namely the groups of structural shifts. Calculations were made within several groups of indicators, as follows: the public and private sectors, output goods, employment, investment and fixed assets. Table 3 provides detailed characteristics of structural shifts.

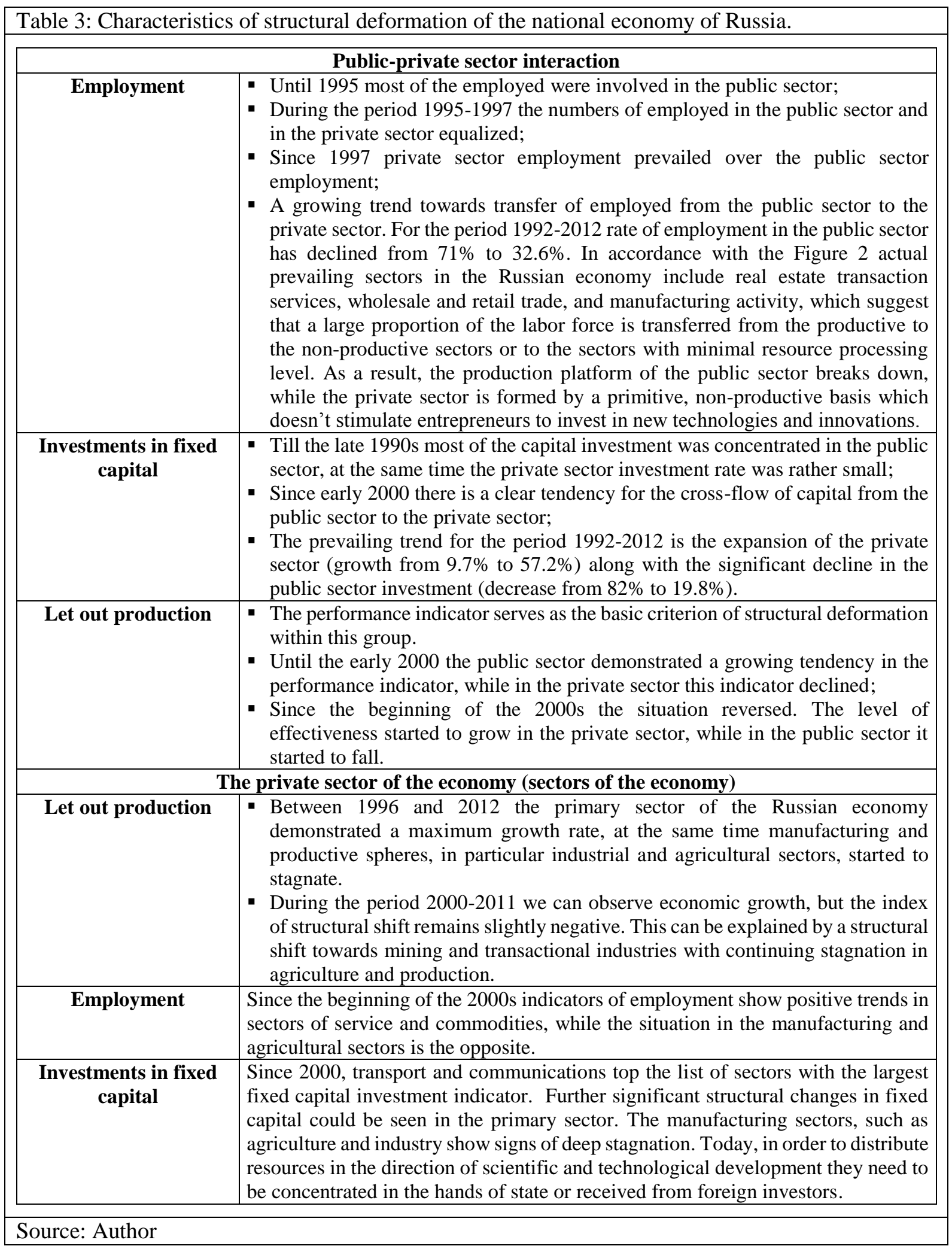


According to the results of the research formulated in the table 3 we can characterize the current structure of the Russian economy, and the following structural deformations that affect it:

- Structural deformation caused by the transition from one management systems to another seriously damaged the structure of industrial production, at the same time it strengthened the positions of the financial and primary sectors. As a result, control over the internal market was partially lost, which was accompanied by difficulties in the external market caused by the technological backwardness of the Russian production complex;

- A rapidly growing structural shift within the financial and primary sectors far exceeds the structural shift in the agricultural and manufacturing sectors; the stagnation of these sectors is accompanied by the process of deindustrialization, while the positive dynamics could be seen quite rarely and remains insufficient;

- The financial and primary sectors outperform the so called "real" sectors of the Russian economy (agriculture, industry) with a huge gap in the balanced financial results, efficiency, and the speed of the structural dynamics in the gross domestic product, obviously taking the leading positions;

- Estimating the structural shifts in industrial sectors based on employment rates, we can note the logical consolidation of the structure which can be characterized as raw materials based and technologically poor. The mass of the structural shift is positive within the primary sectors, and negative within the sectors of technical equipment production;

- The percentage share of employed in the agricultural and industrial sectors is falling rapidly, while in the financial sector this indicator is constantly growing.

\section{Conclusion}

The results of the research allow us to make a series of conclusions about the structural deformations in the Russian economy under the impact of domestic and global challenges:

For the last 15-20 years the size of the public sector of the Russian economy was steadily decreasing without considerable signs of growth, the number of employed remained on at a relatively high level which only increased bureaucratization. The number of employed in the public sector is several times larger than in other developed countries. In the beginning of the reformation period there was a trend towards reduction of employed in the public sector, as a result the public sector dropped two-fold. The diminishing of the public sector happened simultaneously with the growth of the private sector. The highest growth was demonstrated by the primary sector, financial intermediation, and trade with a significant reduction in the manufacturing and agricultural sectors. The private sector of the Russian economy can be characterized as technologically backward. This can be explained by the tendencies mentioned above, when the labor force transfers from productive to the non-productive sectors, it leads to a lack of stimulus to create, promote and commercialize innovative technologies;

Fixed capital investment in the public sector diminished at a significantly higher rate than the expansion of the private sector. The explanation lies in the tendencies described earlier. The investing activity was not always aimed towards technological modernization of basic assets.

The main reason for the structural disbalance of the Russian economy stems not in the high share of the public sector, because its constant decrease allowed the private sector to develop, but in the prioritizing the strategies of development both within the private and public sectors. The issue of the balance between the public and private sectors cannot be considered as a new one, but for the Russian Federation, where the ratio is far from optimal, this issue is a cornerstone of economic development. It's quite conceivable that the share of the public sector can be increased in order to implement structural changes in the Russian economy with simultaneous advancement in effectiveness of the public sector.

\section{References}

Abalkin L. (2002). Logic of economic growth. - M.: Science. 2002. 228.

All-Russian classifier of economic activities. Available at: https://код-оквэд.рф

Barkhatov, V., Belova, I. (2017). External Success Factors of Small and Medium-Sized Enterprises of Russia: Economic Aspect. Country Experiences in Economic Development, Management and Entrepreneurship. Proceedings of the 17th Eurasia Business and Economics Society Conference, 5, 453-468.

Barkhatov V., Belova I., Bents D. (2018). Large-Sized Enterprises in Russia: An Analysis of Federal Districts (2018). Procedia - Social and Behavioral Sciences, 238, 303-312. 
Barkhatov V., Silova E., Bents D., Kapkaev Iu. (2018). Scientific and Technological "Breake" in Russia: Capacity of Monopolistic Structures. Economic and Social Development. Book of Proceedings. 31st International Scientific Conference on Economic and Social Development - "Legal Challenges of Modern World" 2018, 132-140.

Barkhatov V., Bents D., Belova I., Kapkaev Yu. (2018). Large Businesses of Russia: An Industry Analysis. CBU International Conference Proceedings, 6. DOI: http://dx.doi.org/10.12955/cbup.v6.1127

Barkhatov V., Pletnev D. \& Campa A. (2016). Key Success Factors and Barriers for Small Businesses: Comparative Analysis. Procedia - Social and Behavioral Sciences, 221, 29-38.

Bell D. (1999). The Coming of post-industrial society - Academia, 960.

Clark J.B. (1886) The philosophy of wealth: economic principles newly formulated. MA, Ginn\& Company, Publishers, Boston, 280

Glazyev S. (2008). Opportunities and limitations of technical and economic development of Russia in the conditions of structural transformations in the world economy - 2008, 59.

Danilov-Danilyan V. (2001). Flight to the market: ten years later. Moscow : MNEPU, 2001, 232.

Inozemtseva V. (1997). Structuring of social production in the system of post-industrial coordinates. - Russian economic journal. 1997. - No. 11. 59-63.

Quesnay F. (1960). Selected economic works. - Sotsekgiz. 1960. 552.

Kondratyev N., Yakovets Yu., Abalkin L. (2002). Large cycles of conjuncture and the theory of foresight. - M.: Economics, 2002. 766.

May V. (2006). The Russian economy: strengths and weaknesses. - Economic policy. 2006. № 2. 42-45.

Marx K., Engels F. (1964). Compositions : in 30 t. - Moscow: State Policy, 1964. Part III. 674 p.

Rosstat. Available at: http://www.gks.ru/free_doc/doc_2018/rusfig/rus18.pdf

Sukharev O. (2009). Structural task of determining priorities, forms of organization and rules. - Investments in Russia. 2009. No. 2. 20-26.

Schumpeter I. (1982). Theory of economic development. - M.: Progress. 1982. 358.

Yakovets Yu. (1999). Cycles. Crises. Forecasts. - M.: Science. 1999. 447. 